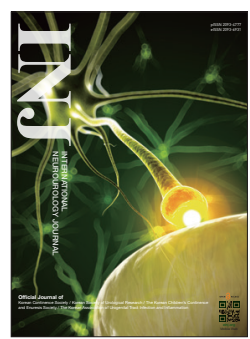

\title{
Expected Next-Generation Drugs Under Development in Relation to Voiding Symptoms
}

\author{
Kyung Jin Chung, Benjamin I. Chung \\ Department of Urology, Stanford University School of Medicine, CA, USA
}

\begin{abstract}
New drug development is a high-risk venture, but if successful, will bring great revenues to those willing to accept the risk. In the field of urology, in particular for lower urinary tract symptoms (LUTS), the recent successful landing of drugs (e.g., mirabegron, botulinum toxin $\mathrm{A}$, and tadalafil) has resulted in increased interest in new drug development. Benign prostatic hyperplasia and overactive bladder syndrome, representative LUTS diseases, are attractive targets because of their prevalence and market size in the field of urology. Additionally, the awareness about new stream of research is very important not only because of the market size and economic factors, but also because to keep steady attention to these research for the researcher's. We have reviewed a selection of new drugs currently under development for the treatment of the two aforementioned diseases and hope to offer urologists an overview of the current situation and future directions in the field of urology.
\end{abstract}

Keywords: Lower Urinary Tract Symptoms; Prostatic Hyperplasia; Urinary Bladder, Overactive; Clinical trials as topic

- Conflict of Interest: No potential conflict of interest relevant to this article was reported.

\section{INTRODUCTION}

Lower urinary tract symptoms are not a disease that can affect survival, but are closely related to quality of life and form a huge drug market worldwide. These drugs can be prescribed not merely according to the relevant symptom, but also according to the diagnosed disease. In relation to voiding symptoms, approximately seven groups of drugs are used clinically, such as alpha-adrenoceptor antagonists, 5-alpha reductase inhibitors, antimuscarinics, phosphodiesterase type 5 (PDE5) inhibitors, beta-agonists, botulinum toxin (botox), and phytotherapic supplements [1]. However, there are many trials to develop new drugs for the improved treatment of voiding symptoms. Benign prostatic hyperplasia (BPH) and overactive bladder syndrome $(\mathrm{OAB})$, which are representative diseases of voiding dysfunc- tion, are the main targets of these drugs, and tremendous efforts are underway to develop more potent and beneficial drugs for these diseases.

$\mathrm{BPH}$ is a conventional disease, which is characterized by hyperplasia according to aging, bladder outlet obstruction, following lower urinary tract symptoms (LUTS) [2]. At present, the main drugs for treatment of $\mathrm{BPH}$ are alpha-adrenergic antagonists and 5-alpha-reductase inhibitors, but new drugs with different underlying mechanisms are in development [3]. The size of the global BPH drug market was US $\$ 3.2$ billion in 2010 and, with an annual growth rate of $6.4 \%$, would reach US $\$ 5.2$ billion by 2024 [4]. Although the impending expiration of the patents of alfuzosin or dutasteride might be obstacles, the development of powerful drugs such as tadalafil will enable the expansion of the BPH-related drug market. Furthermore, the rapidly aging of

Corresponding author: Benjamin I. Chung (iD https://orcid.org/0000-0001-9660-2732 Department of Urology, Stanford University School of Medicine, 300 Pasteur Drive S-287, Stanford, California 94305 USA

E-mail: bichung@stanford.edu/ Tel: +1-650-725-5544 / Fax: +1-650-723-2300

Submitted: June 14, 2017 / Accepted: June 19, 2017 
population also supports the potential growth of this market [4].

$\mathrm{OAB}$ is the sudden strong onset of urge to urinate, with or without urge incontinence, without a definite underlying disease [5]. The history of this mainly symptom-based disease is short; it was proposed by Alan Wein and Paul Abrams in late 1997. Although the establishment of the disease category is fairly recent, and it was stigmatized as a "created disease" when first proposed, the OAB-related market has grown rapidly rate to attain a global market size of approximately US $\$ 3$ billion in 2015 and is currently growing by $1.14 \%$ annually [6]. Antimuscarinic agents are still the most representative drugs for $\mathrm{OAB}$, but recent treatments for $\mathrm{OAB}$ have shown great changes, such as the emergence of new acting types of drugs, including beta-3 adrenergic agonists, PDE5 inhibitors, and botox.

Whether it is because an increase in the number of patients that has resulted from an aging population, the emergence of new drugs arising from continuous research and academic development, or, in the worst-case scenario, the aggressive investment and marketing of the global pharmaceuticals, the drug market for voiding-related symptoms has experienced annual growth and new drugs are in continuous development to support this reality. The prospect of new drugs for the treatment $\mathrm{BPH}$ or $\mathrm{OAB}$ is important from medical or pharmaceutical viewpoints. For researchers, it can help them obtain broad and profound knowledge and insight into future treatments and keep their research focused in the right direction; for health care providers, it can enable them to make decisions about treatment regimen and energize the interventional clinical trial; and for pharmaceutical companies, it can allow proper response to the fast development and growth of the drug market, enabling aggressive investment in research that will make an ideal business plan.

In this paper, we wish to provide you with an overview of new drug development related to voiding dysfunction.

\section{NEXT GENERATION DRUGS FOR BPH}

At present, the 2 major categories about $\mathrm{BPH}$ medical treatment are alpha-adrenergic antagonists and 5-alpha-reductase inhibitors, but, over 60 candidate drugs are in development with multiple mechanisms of action [3]. These suggested action mechanisms include super-selective alpha adrenergic antagonists, vasopressins, luteinizing hormone-releasing hormone (LHRH) antagonists, antiandrogens, PDE5 inhibitors, gonadotrophin-releasing hormone $(\mathrm{GnRH})$ antagonists, flavonoids, and vaccines [7].

The following summary describes drugs mainly in clinical phase 3, which are closest to clinical use [8]. NX-1207, a fexapotide triflutate with selective apoptotic properties, is administered by transrectal ultrasound-guided intraprostatic injection [9]. Although the injection method is somewhat difficult and invasive, it is known to effectively reduce the volume of the prostate gland and symptomatic improvement has been seen in both short-term and long-term studies [8].

PRX-302 (topsalysin) is another injectable modified recombinant peptide which might be selectively activated by prostatespecific antigen (PSA), which induces prostatic cell apoptosis without damaging the surrounding tissue and nerves [10]. After activation with PSA, PRX-302 is combined with other PRX302, which induces cell apoptosis through the formation of transmembrane pores. This PSA-specific selectivity reduces the effects on nonprostate tissue and ensures for high safety of treatment [11].

Elagolix is an orally administered non-peptide $\mathrm{GnRH}$ antagonist [12]. It has a shorter acting time than other GnRH antagonists administered by a conventional subcutaneous depot injection, such as Leuplin and Goserelin, which means it has two advantages: one, it has a fast action time; two, it is easy to quit the drug in the event of appearance of adverse effects. Therefore, studies of the drug are in progress for the treatment of $\mathrm{BPH}$, prostate cancer, and endometriosis [13].

Udenafil is a PDE5 inhibitor that targets intracellular signaling pathways. One such example is tadalafil, which is already used clinically [14]. Cyclic nucleotide monophosphate (cyclic GMP) is known to be an important mediator of the bladder and urethral vascular mechanisms. PDE5 inhibitors inhibit the degradation of the second messenger, cyclic GMP, and may play a role in the treatment of LUTS [14].

Equol is a metabolite of daidzein, one of the major isoflavones in soybean. It acts as a 5 -alpha-reductase inhibitor in the prostate and is known to inhibit the hormones that cause prostate cancer and male baldness [15]. DA-6034 is a synthetic derivative of the flavonoid eupatilin, which is known to have antiinflammatory function [16]. In addition, HCP1101, a combination of 5-alpha-reductase inhibitors, AMV110, a vaccine series, and high-dose tamsulosin are in phase III clinical trials.

Many different compounds, including ozarelix (LHRH antagonist), VA106483 (vasopressin V2 agonist), and andrine (dihydrotestosterone), which have been developed for the treatment of $\mathrm{BPH}$ are in the second stage of clinical development. 
Additionally, AKP-002 (PDE9 inhibitor), tadalafil/tamsulosin combination, and prostide (herbal extract) are in phase I clinical development. Finally, other treatments, such as cell therapy, anticancer vaccines, and contraceptives have also been studied as potential treatments for $\mathrm{BPH}$ [17].

\section{NEXT GENERATION DRUGS FOR OAB}

Unlike BPH drug development, a number of drugs currently in development for the treatment of $\mathrm{OAB}$, such as antimuscarinic agents and beta- 3 agonists, which is similar to the existing therapeutics.

A representative candidate antimuscarinic agent, tarafenacin, is known to have superior selectivity to M3 in comparison with M2; it was shown to have 200 times greater selectivity [18] and its characteristics include less constipation than conventional anticholinergic agents and dry mouth as the most common side effect [19]. THVD-201 (Tolenix) and THVD-202 have been developed for a once daily or twice daily regimen, which is combination of tolterodine, an antimuscarinics, and pilocarpine, a modified-release muscarinic agonist [20]. These drugs are designed to reduce the main adverse effects of anticholinergic drugs, such as dry mouth and constipation, which directly affect drug compliance [21]. The results of clinical trials have been positive and studies are likely to be published soon. Afacifencin (MP-986), another drug of interest, which is a combination of a nonselective muscarinic antagonist and a $\mathrm{Na}+$ channel blocker, blocks the afferent nerve pathway of the urinary bladder [22].

Similar to a recently successfully marketed drug, mirabegron, beta-3 agonists relieve $\mathrm{OAB}$ symptoms through the relaxation of the detrusor muscle, the suppression of uninhibited bladder contraction, and the reduction of the afferent nerve pathway [23]. This is therefore a next-generation drug of great interest. GW427353 (Solabegron), which has shown reduction of bladder contraction and proven efficacy and safety in the second phase of clinical trial, and ritobegron are in phase III clinical trials. A number of other drugs are under investigation $[24,25]$. The combination therapy of antimuscarinics and beta3 agonists is also an attractive therapeutic candidate; representative drugs from each series, mirabegron and solifenacin, are in phase III clinical trials [26].

In addition, several medications are under investigation; some are expected to be effective, but others, though they have theoretical basis, might be ineffective. Rho-kinase pathway up- regulation was found in idiopathic detrusor overactivity, bladder changes in diabetes, and obstruction to retention so the drug in relation to this pathway has been an interesting target for the inhibition of bladder overactivity [27]. The vitamin D3 agonist, elocalcitol, is a RhoA/Rho kinase inhibitor and is under investigation for its effects against $\mathrm{OAB}$. Although it has been reported as effective for women with $\mathrm{OAB}$, further extensive studies are needed [28]. Nerve growth factor (NGF) has also been suggested as a potential therapeutic medication and a possible diagnostic biomarker. However, the development of tanezumab, a humanized NGF antibody, was ceased owing to its side effects [29]. Prostaglandin $\mathrm{E}_{2}$ was shown to activate bladder contraction via the afferent nerve through the EP1 receptor, which was attractive to the researchers as it is increased in patients with LUTS [30]. However, the actual efficacy of the EP1 receptor antagonist in $\mathrm{OAB}$ patients in clinical trials was not satisfactory [31]. Considering the action mechanism, the $\mathrm{K}+$ channel opener also has been suggested as a possible treatment of $\mathrm{OAB}$, but the clinical data showed no satisfactory results. In addition, cannabinoids and transient receptor potential (TRP) channel antagonists have been repeatedly investigated, but no candidates have yet emerged [32-34].

\section{CONCLUSIONS}

The development of a new drug presents many opportunities: for patients to ameliorate their symptoms or disease; to reinforce the treatment effect; and for doctors and researchers to improve their treatment results and to make progress on their own research. Furthermore, it is an excellent opportunity for pharmaceutical companies to increase their market share, generate profits, and eliminate competitors. However, the development of these new drugs requires long-term effort, excessive costs, and involves a high risk of failure. Therefore, the indomitable will and continued investment and attention of the researchers, government, and pharmaceutical companies that support the research are essential.

A variety of mechanisms and new categories of drug candidates have been studied for various forms of voiding dysfunction including BPH and OAB. Many of them are close to clinical applications and commercialization, which provide hope to patients waiting for cures. It is expected that the introduction of more efficacious medications will be of significant help to the patients who have not had satisfactory experiences with the currently available treatments. 


\section{REFERENCES}

1. Brasure M, MacDonald R, Dahm P, Olson CM, Nelson VA, Fink $\mathrm{HA}$, et al. Newer medications for lower urinary tract symptoms attributed to benign prostatic hyperplasia: a review. Rockville (MD); Agency for Healthcare Research and Quality (US); 2016.

2. Roehrborn CG. Benign prostatic hyperplasia: an overview. Rev Urol 2005;7 Suppl 9:S3-14.

3. Dahm P, Brasure M, MacDonald R, Olson CM, Nelson VA, Fink $\mathrm{HA}$, et al. Comparative effectiveness of newer medications for lower urinary tract symptoms attributed to benign prostatic hyperplasia: a systematic review and meta-analysis. Eur Urol 2017;71:57081.

4. Benign prostatic hyperplasia treatment market value to reach nearly $\$ 5$ billion [Internet] Montville (NJ): Drug Development \& Delivery; c2017 [posted 2015 Sept 16; cited 2017 June 1]. Available from: http://www.drug-dev.com/Main/Back-Issues/Benign-ProstaticHyperplasia-Treatment-Market-Valu-993.aspx\#sthash.ZIFCc6Hb. dpuf.

5. Abrams P, Cardozo L, Fall M, Griffiths D, Rosier P, Ulmsten U, et al. The standardisation of terminology of lower urinary tract function: report from the Standardisation Sub-committee of the International Continence Society. Neurourol Urodyn 2002;21:167-78.

6. Fiore K, Fauber J, Wynn M. Drug firms helped create $\$ 3$ billion overactive bladder market [Internet]. MedPage Today and Milwaukee Journal Sentinel; 2016 [cited 2017 June 3]. Available from: http://www.jsonline.com/story/news/investigations/2016/10/16/ overactive-bladder-drug-companies-helped-create-3-billion-market/92030360.

7. Hashim H, Abrams P. Emerging drugs for the treatment of benign prostatic obstruction. Expert Opin Emerg Drugs 2010;15:159-74.

8. Kunit T, Lusuardi L. An evidence-based review of NX1207 and its potential in the treatment of benign prostatic hyperplasia. Res Rep Urol 2014;6:67-70.

9. Fadok VA, Voelker DR, Campbell PA, Cohen JJ, Bratton DL, Henson PM. Exposure of phosphatidylserine on the surface of apoptotic lymphocytes triggers specific recognition and removal by macrophages. J Immunol 1992;148:2207-16.

10. Magistro G, Stief CG, Gratzke C. New intraprostatic injectables and prostatic urethral lift for male LUTS. Nat Rev Urol 2015; 12:461-71.

11. Elhilali MM, Pommerville P, Yocum RC, Merchant R, Roehrborn CG, Denmeade SR. Prospective, randomized, double-blind, vehicle controlled, multicenter phase IIb clinical trial of the pore forming protein PRX302 for targeted treatment of symptomatic benign prostatic hyperplasia. J Urol 2013;189:1421-6.

12. Ezzati M, Carr BR. Elagolix, a novel, orally bioavailable GnRH antagonist under investigation for the treatment of endometriosis-related pain. Womens Health (Lond) 2015;11:19-28.

13. Diamond MP, Carr B, Dmowski WP, Koltun W, O’Brien C, Jiang P, et al. Elagolix treatment for endometriosis-associated pain: results from a phase 2, randomized, double-blind, placebo-controlled study. Reprod Sci 2014;21:363-71.

14. Uckert S, Oelke M. Phosphodiesterase (PDE) inhibitors in the treatment of lower urinary tract dysfunction. Br J Clin Pharmacol 2011;72:197-204.

15. Bae M, Woo M, Kusuma IW, Arung ET, Yang CH, Kim YU. Inhibitory effects of isoflavonoids on rat prostate testosterone $5 \alpha$-reductase. J Acupunct Meridian Stud 2012;5:319-22.

16. Lee J, Shin KH, Kim JR, Lim KS, Jang IJ, Chung JY. Pharmacokinetics, safety and tolerability of DA-6034, an anti-inflammatory agent, after single and multiple oral administrations in healthy volunteers. Clin Drug Investig 2014;34:37-42.

17. Pharma F. Global benign prostatic hyperplasia market and competitive landscape highlights-2016. Dublin (Ireland): Research and Markets; 2016.

18. Salcedo C, Davalillo S, Cabellos J, Lagunas C, Balsa D, Pérez-DelPulgar S, et al. In vivo and in vitro pharmacological characterization of SVT-40776, a novel M3 muscarinic receptor antagonist, for the treatment of overactive bladder. Br J Pharmacol 2009;156:80717.

19. Song M, Kim JH, Lee KS, Lee JZ, Oh SJ, Seo JT, et al. The efficacy and tolerability of tarafenacin, a new muscarinic acetylcholine receptor M3 antagonist in patients with overactive bladder; randomised, double-blind, placebo-controlled phase 2 study. Int J Clin Pract 2015;69:242-50.

20. Thiagamoorthy G, Cardozo L, Robinson D. Current and future pharmacotherapy for treating overactive bladder. Expert Opin Pharmacother 2016;17:1317-25.

21. Dmochowski RR, Staskin DR, Duchin K, Paborji M, Tremblay TM. Clinical safety, tolerability and efficacy of combination tolterodine/pilocarpine in patients with overactive bladder. Int J Clin Pract 2014;68:986-94.

22. Zacche MM, Giarenis I, Cardozo L. Phase II drugs that target cholinergic receptors for the treatment of overactive bladder. Expert Opin Investig Drugs 2014;23:1365-74.

23. Ellsworth P. Treatment of overactive bladder symptoms beyond antimuscarinics: current and future therapies. Postgrad Med 2012; 124:16-27.

24. Biers SM, Reynard JM, Brading AF. The effects of a new selective 
beta3-adrenoceptor agonist (GW427353) on spontaneous activity and detrusor relaxation in human bladder. BJU Int 2006;98:1310-4.

25. Andersson KE. Drug therapy of overactive bladder--what is coming next? Korean J Urol 2015;56:673-9.

26. Abrams P, Kelleher C, Staskin D, Rechberger T, Kay R, Martina R, et al. Combination treatment with mirabegron and solifenacin in patients with overactive bladder: efficacy and safety results from a randomised, double-blind, dose-ranging, phase 2 study (Symphony). Eur Urol 2015;67:577-88.

27. Morelli A, Squecco R, Failli P, Filippi S, Vignozzi L, Chavalmane AK, et al. The vitamin D receptor agonist elocalcitol upregulates L-type calcium channel activity in human and rat bladder. Am J Physiol Cell Physiol 2008;294:C1206-14.

28. Digesu GA, Verdi E, Cardozo L, Olivieri L, Khullar V, Colli E. Phase IIb, multicenter, double-blind, randomized, placebo-controlled, parallel-group study to determine effects of elocalcitol in women with overactive bladder and idiopathic detrusor overactivity. Urology 2012;80:48-54.

29. Leite VF, Buehler AM, El Abd O, Benyamin RM, Pimentel DC, Chen J, et al. Anti-nerve growth factor in the treatment of low back pain and radiculopathy: a systematic review and a meta-analysis. Pain Physician 2014;17:E45-60.

30. Atobe M, Naganuma K, Kawanishi M, Morimoto A, Kasahara K, Ohashi S, et al. Discovery of 2-(1H-indazol-1-yl)-thiazole derivatives as selective $\mathrm{EP}(1)$ receptor antagonists for treatment of overactive bladder by core structure replacement. Bioorg Med Chem Lett 2014;24:1327-33.

31. Chapple CR, Abrams P, Andersson KE, Radziszewski P, Masuda T, Small M, et al. Phase II study on the efficacy and safety of the EP1 receptor antagonist ONO-8539 for nonneurogenic overactive bladder syndrome. J Urol 2014;191:253-60.

32. Petkov GV. Role of potassium ion channels in detrusor smooth muscle function and dysfunction. Nat Rev Urol 2011;9:30-40.

33. Ruggieri MR Sr. Cannabinoids: potential targets for bladder dysfunction. Handb Exp Pharmacol 2011;(202):425-51.

34. Andersson KE, Gratzke C, Hedlund P. The role of the transient receptor potential (TRP) superfamily of cation-selective channels in the management of the overactive bladder. BJU Int 2010;106:111427. 